\title{
Microbial Contamination of Nebulization Solution and Its Measures
}

\author{
Shigeharu Oie, ${ }^{a}$ Daiki Makieda, ${ }^{a, b}$ Shiro Ishida, ${ }^{b}$ Yoshiro OKano, ${ }^{b}$ and Akira KamiYA ${ }^{*}, a$ \\ ${ }^{a}$ Department of Pharmacy, Yamaguchi University Hospital; 1144 Kogushi, Ube 755-8505, Japan: and ${ }^{b}$ Department of \\ Pharmaceutical Care and Clinical Pharmacy, Faculty of Pharmaceutical Sciences, Tokushima Bunri University; 180 \\ Yamashiro-cho, Tokushima, Tokushima 770-8514, Japan. Received July 7, 2005; accepted October 24, 2005
}

\begin{abstract}
We evaluated the microbial contamination of nebulization solutions in medication cups from a total of 76 ultrasonic nebulizers in use in 10 hospitals. In addition, an interview survey was given to nurses to evaluate the disinfection methods of these ultrasonic nebulizers. Of a total of 76 nebulization solution samples, $11(14.5 \%)$ were contaminated with $10-10^{2}$ colony-forming units $(\mathrm{CFU}) / \mathrm{ml}$ and $9(11.8 \%)$ with $10^{3}-10^{5} \mathrm{CFU} / \mathrm{ml}$. The major contaminants were glucose non-fermentative bacilli such as Burkholderia cepacia, CDC gr.IV C-2, and Sphingomonas paucimobilis. Comparison of microbial contamination between the frequencies of disinfection showed a significantly lower number of contaminated samples when the cups were disinfected once daily than when disinfected once at intervals of $2-7 \mathrm{~d}(p=0.00037)$. In addition, comparison between the presence and absence of preservatives contained in the nebulization solution showed a significantly lower number of contaminated samples in the presence, rather than in the absence, of preservatives $(p=0.00001)$. These results show that disinfection of ultrasonic nebulizers at $24-\mathrm{h}$ intervals is desirable. In particular, when nebulization solutions not containing preservatives are used, disinfection at $24-\mathrm{h}$ intervals is indispensable.
\end{abstract}

Key words ultrasonic nebulizer; nebulization solution; microbial contamination; disinfection

Nebulization solutions contaminated with microorganisms can be sources of infection. ${ }^{1-7)}$ However, since nebulization solutions are classified as external preparations, their hygienic management tends to be neglected at present. ${ }^{8-12)} \mathrm{We}$ investigated the microbial contamination of nebulization solutions in use from ultrasonic nebulizers commonly used in nebulizer therapy. In addition, the methods of preventing the microbial contamination of these nebulization solutions were evaluated.

\section{MATERIALS AND METHODS}

Microbial Contamination of Nebulization Solutions Between January and March, 2004, we quantified and identified microorganisms (bacteria, fungi) in nebulization solutions from medication cups of a total of 76 ultrasonic nebulizers in use in 10 hospitals in Yamaguchi Prefecture, Japan.

The samples were diluted $10,10^{2}, 10^{3}$ and $10^{4}$ times with normal saline solution. Pipettes were used to transfer $0.2 \mathrm{ml}$ of the undiluted or diluted samples to trypticase soy agar or Sabouraud dextrose agar (each agar contained $0.2 \%$ Tween 80 and $0.07 \%$ soya lecithin as inactivators). Plates were streaked with a glass "hockey stick," and incubated at $30^{\circ} \mathrm{C}$ for 24 to $72 \mathrm{~h}$ (trypticase soy agar) and at $25^{\circ} \mathrm{C}$ for 2 to $7 \mathrm{~d}$ (Sabouraud dextrose agar). Colonies were counted on each plate to determine viable cells, and the organisms were identified by Gram staining, morphological examination, oxidation-fermentation test, cytochrome-oxidase test and an API system (bio Merieux sa, France).

Survey of Ultrasonic Nebulizer Disinfection Methods and Types of Nebulization Solution An interview survey was given to nurses in charge to evaluate the frequency and method of disinfection of ultrasonic nebulizer equipment (nebulizer chamber and aerosol hose). In addition, the types of nebulization solution and the presence or absence of preservatives contained in the nebulization solutions were investigated.

The number of contaminated samples ( $\geq 10$ colony-form- ing units $(\mathrm{CFU}) / \mathrm{ml})$ was compared by the Wilcoxon $U$-test between those nebulizers disinfected once daily and those disinfected once at intervals of $2-7 \mathrm{~d}$, and between the presence and absence of preservatives in nebulization solutions.

Viability of Contaminants in Various Types of Nebulization Solution The two microorganism species used for viability tests in various types of nebulization solutions were Serratia marcescens IFO 3736, and one strain of Bulkholderia cepacia. $S$. marcescens were purchased from the Institute for Fermentation (Osaka, Japan). B. cepacia were isolated from a nebulization solution in use (dibekacin/betamethasone solution). ${ }^{8)}$ Stock cultures of $S$. marcescens and B. cepacia were maintained on trypticase soy agar at $4{ }^{\circ} \mathrm{C}$.

$S$. marcescens and $B$. cepacia were incubated on trypticase soy agar at $30^{\circ} \mathrm{C}$ for $48 \mathrm{~h}$, harvested, and suspended with sterile physiological saline to obtain about $10^{8} \mathrm{CFU} / \mathrm{ml}$. About $10^{8} \mathrm{CFU} / \mathrm{ml}$ of each strain were diluted in sterile physiological saline to obtain about $10^{5} \mathrm{CFU} / \mathrm{ml}$, and an aliquot $(50 \mu \mathrm{l})$ of this microbial solution was inoculated into $4.95 \mathrm{ml}$ of each nebulization solution and swirled for $10 \mathrm{~s}$. The samples were incubated at $30^{\circ} \mathrm{C}$. Plate counts were performed at 6,24 , and $48 \mathrm{~h}$ and at $7 \mathrm{~d}$ using trypticase soy agar containing $0.2 \%$ Tween 80 and $0.07 \%$ soya lecithin. This experiment was performed twice, and the mean viable count was calculated.

Measurement of $\mathrm{pH}$ and Water Activity of Nebulization Solution The $\mathrm{pH}$ of the nebulization solutions used in the viability test was measured using a $\mathrm{pH}$ meter $\mathrm{F}-7$ type (Horiba Inc., Kyoto). Water activity (Aw) was measured using a water activity measurement system WA-40 (Gunze Inc., Tokyo).

\section{RESULTS}

Ultrasonic Nebulizer Disinfection Methods and Types of Nebulization Solution In all 10 investigated hospitals, nebulizer chambers (medication cups) and nebulizer hoses of ultrasonic nebulizers were disinfected by immersion in 


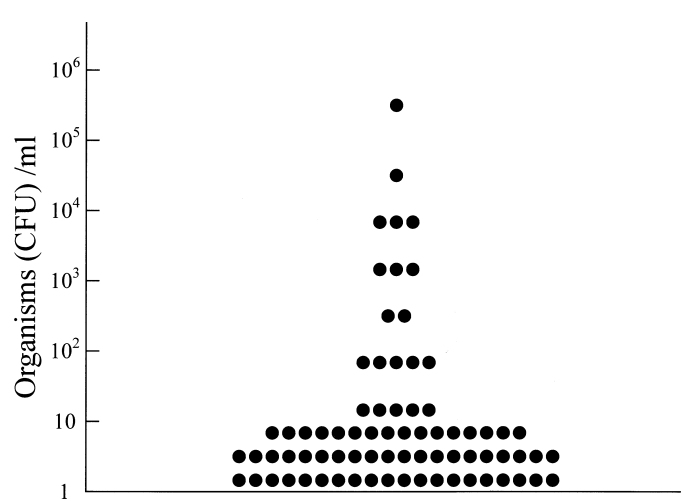

Fig. 1. Microbial Contamination of In-use Nebulization Solutions $(n=76)$

$0.01 \%(100 \mathrm{ppm})$ sodium hypochlorite for $1 \mathrm{~h}$ or more. Ultrasonic nebulizers were disinfected at 24-h intervals in 6 hospitals and at intervals of $2-7 \mathrm{~d}$ in the other 4 hospitals. Nebulization solution samples were collected from medication cups before disinfection on the day of nebulizer disinfection, but we did not investigate the interval between the previous disinfection to sample collection. The types of nebulization solution not containing preservatives included $0.9 \%$ sodium chloride for injection, distilled water for injection and Fungizone $^{\circledR}$ solution $(2.5 \mathrm{mg} / \mathrm{ml})$. The types of nebulization solution containing preservatives included Bisolvon ${ }^{\circledR}+$ distilled water for injection, Bisolvon ${ }^{\circledR}+$ Venetolin $^{\circledR}+$ distilled water

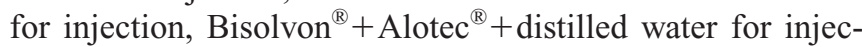
tion, Bisolvon ${ }^{\circledR}+$ Meptin ${ }^{\circledR}+$ distilled water for injection, Bisolvon $^{\circledR}+$ Asupul $^{\circledR}+$ distilled water for injection, and Bisolvon ${ }^{\circledR}+$ Inolin $^{\circledR}+$ distilled water for injection. Here, Bisolvon $^{\circledR}$, Venetolin $^{\circledR}$, Alotec $^{\circledR}$, Meptin $^{\circledR}$, Asupul $^{\circledR}$ and Inolin ${ }^{\circledR}$ were diluted $1: 2-10$ with distilled water for injection.

Microbial Contamination of Nebulization Solutions Of the 76 samples of nebulization solution from the medication cups of the ultrasonic nebulizers, 20 (26.3\%) were contaminated with $\geq 10 \mathrm{CFU} / \mathrm{ml}$. The contamination level was $10-10^{2} \mathrm{CFU} / \mathrm{ml}$ in 11 samples $(14.5 \%), 10^{3}-10^{5} \mathrm{CFU} / \mathrm{ml}$ in $9(11.8 \%)$ (Fig. 1). The major contaminants and their relative frequencies (\%) were Burkholderia cepacia (35\%), glucose non-fermentative bacilli that could not be identified (30\%), CDC gr.IV C-2 (15\%), Acinetobacter baumannii/calcoaceticus (5\%), Sphingomonas paucimobilis (5\%), Stenotrophomonas maltophilia (5\%), and Comamonas acidovorans $(5 \%)$.

Comparison between the disinfection frequencies showed a significantly lower number of contaminated samples with disinfection once daily in 6 hospitals than with disinfection at intervals of $2-7 \mathrm{~d}$ in the other 4 hospitals $(p=0.00037$; Fig. 2).

Comparison between the presence and absence of preservatives in nebulization solution showed a significantly lower number of contaminated samples in the presence of preservatives than in their absence $(p=0.00001$; Fig. 3$)$. Even among samples of nebulization solution containing preservatives that were disinfected at 24-h intervals, 2 showed contamination at a level of $10 \mathrm{CFU} / \mathrm{ml}$.

Viability of Contaminants in Nebulization Solutions Table 1 shows the preparations used in the test, the concentration of preservatives contained in each, and their $\mathrm{pH}$ and water activity (Aw). Though not shown in Table 1 , the $\mathrm{pH}$

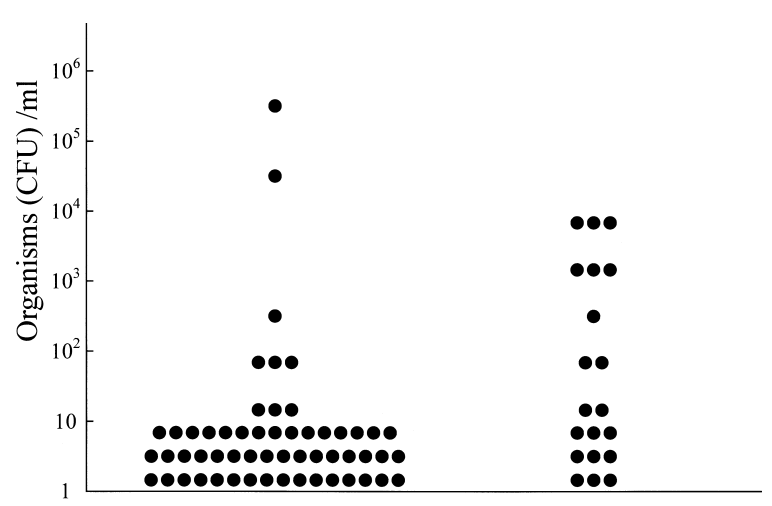

Once daily

Once at intervals of 2-7 days

Fig. 2. Microbial Contamination of In-use Nebulization Solutions According to Disinfection Frequency $(n=76)$

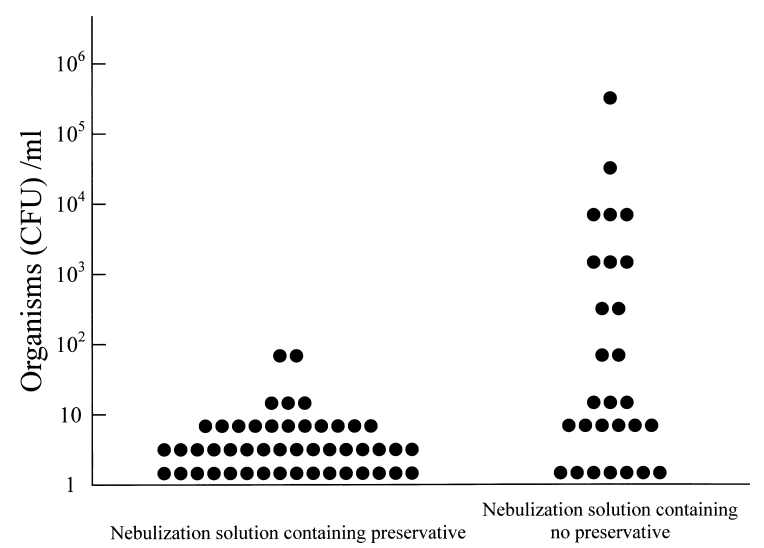

Fig. 3. Microbial Contamination of In-use Nebulization Solutions Containing and Not Containing Preservative $(n=76)$

and Aw of $1: 2$ and $1: 10$ dilutions of these preparations were measured and confirmed to be similar to those of the corresponding preparations.

Both $S$. marcescens and B. cepacia grew in those nebulization solutions not containing preservative $(0.9 \%$ sodium chloride for injection, distilled water for injection, Fungizon ${ }^{\circledR}$ solution) (Fig. 4). In the nebulization solutions containing preservatives, $S$. marcescens did not grow in either the undiluted preparations or their dilutions, while B. cepacia did not grow in the undiluted preparations but grew in some of their dilutions (Fig. 5).

\section{DISCUSSION}

This survey showed microbial contamination $\left(10-10^{5}\right.$ $\mathrm{CFU} / \mathrm{ml})$ in $20(26.3 \%)$ of the 76 samples of investigated nebulization solutions. There have been no previous detailed surveys that evaluated the microbial contamination of nebulization solutions, but awareness of the high susceptibility of nebulization solutions to microbial contamination may be necessary.

Microbial contamination of nebulization solutions seemed to have been caused by contaminated ultrasonic nebulizers. Indeed, comparison between the frequencies of the disinfection of ultrasonic nebulizers in this study showed a significantly lower number of contaminated samples with disinfection once daily, compared with disinfection at intervals of 
Table 1. Composition, $\mathrm{pH}$ and Water Activity of Preparations Used

\begin{tabular}{|c|c|c|c|c|}
\hline Preparation & Name & $\begin{array}{l}\text { Preservative content and } \\
\text { its concentration }\end{array}$ & $\mathrm{pH}$ & $\begin{array}{l}\text { Water activity } \\
(\%)\end{array}$ \\
\hline $0.9 \%$ Sodium chloride for injection & $0.9 \%$ Sodium chloride for injection "Hikari" & -a) & 6.7 & 95.6 \\
\hline Distilled water for injection & Distilled water for injection "Hikari" & - & $\mathrm{NT}^{b)}$ & NT \\
\hline Amphotericin B & Fungizon $^{\circledR}$ solution $(2.5 \mathrm{mg} / \mathrm{ml})$ & - & 7.5 & 96.4 \\
\hline Procaterol hydrochloride & Meptin ${ }^{\circledR}$ inhalation solution & Benzalkonium chloride, $0.01 \%$ & 3.6 & 95.9 \\
\hline Salbutamol sulfate & Venetlin $^{\circledR}$ inhalation solution & Benzalkonium chloride, $0.01 \%$ & 3.6 & 96.7 \\
\hline Orciprenaline sulfate & Alotec $^{\circledR}$ inhalation solution & $\begin{array}{l}\text { Sodium metabisulphite, } 0.01 \% \\
\text { Disodium edetate, } 0.05 \%\end{array}$ & 3.2 & 95.9 \\
\hline Trimetoquinol hydrochloride & Inolin ${ }^{\circledR}$ inhalation solution & $\begin{array}{l}\text { Methyl hydroxybenzoate, } 0.05 \% \\
\text { Sodium pyrosulphite, } 0.025 \%\end{array}$ & 3.1 & 95.7 \\
\hline$d l$-Isoproterenol hydrochloride & Asupul $^{\mathbb{B}}$ inhalation solution & $\begin{array}{l}\text { Chlorobutanol, } 0.5 \% \\
\text { Sodium metabisulphite, } 0.3 \%\end{array}$ & 3.5 & 95.0 \\
\hline Bromhexine hydrochloride & Bisolvon ${ }^{\circledR}$ inhalation solution & Methyl hydroxybenzoate, $0.1 \%$ & 2.8 & 96.2 \\
\hline
\end{tabular}

a) -, no preservatives. b) NT, not tested.

(a) Serratia marcescens

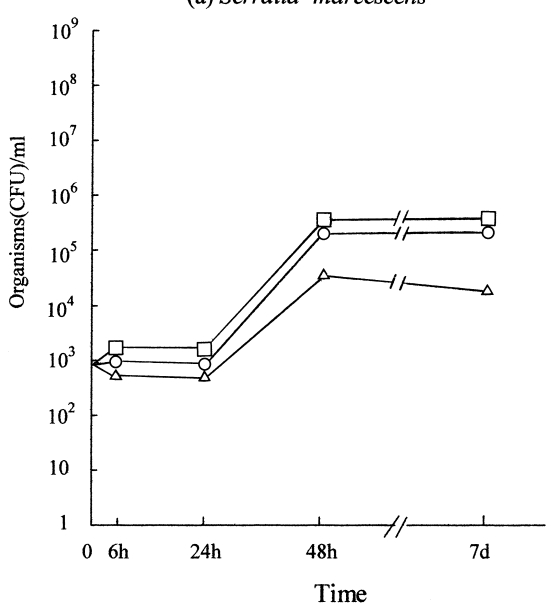

(b) Burkholderia cepacia

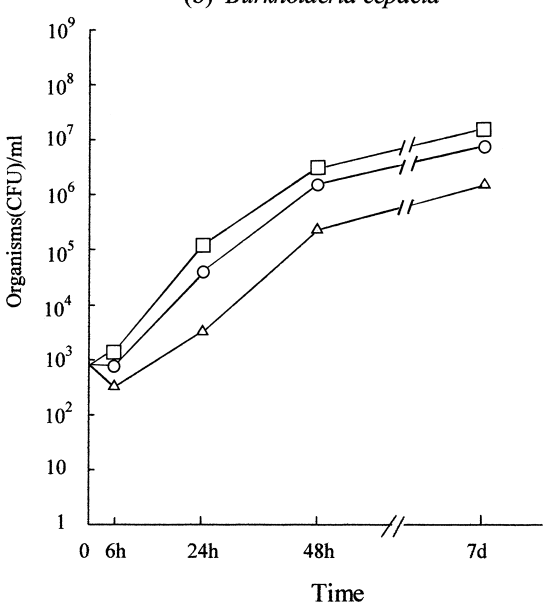

Fig. 4. Viability of Serratia marcescens (a) and Burkholderia cepacia (b) at $30^{\circ} \mathrm{C}$ in Nebulization Solutions Containing No Preservative: $0.9 \%$ Sodium Chloride for Injection $(\bigcirc)$, Distilled Water for Injection $(\triangle)$, and Fungizon ${ }^{\mathbb{Q}}$ Solution $(\square)$

$2-7 \mathrm{~d}(p=0.00037)$. In the viability test, $S$. marcescens and $B$. cepacia grew rapidly in nebulization solutions not containing preservatives, showing about a 1000-fold increase in their levels after $48 \mathrm{~h}$ (Fig. 4). Therefore, we recommend disinfection of ultrasonic nebulizer equipment (nebulizer chamber and nebulizer hose) at least at 24-h intervals. In all the 10 hospitals surveyed in this study, sodium hypochlorite was used for the disinfection of ultrasonic nebulizer equipment. Sodium hypochlorite is an appropriate disinfectant because of its bactericidal activity against glucose non-fermentative bacilli such as Burkholderia cepacia that are frequently detected as contaminants in aerosol solutions, and unlike alcohol, this disinfectant negligibly damages plastic materials. ${ }^{13)}$ Contamination at the $10^{5} \mathrm{CFU} / \mathrm{ml}$ level was observed in 1 of the samples disinfected once daily. We speculated that the medication cup became contaminated with water in the action tank when the patient handled the cup. Indeed, examination of the water in this action tank confirmed consistency between the contaminant species in the water in the action tank and that in this sample.

On the other hand, the number of contaminated samples was significantly lower $(p=0.00001)$ in nebulization solutions containing preservative (such as Bisolvon ${ }^{\circledR}+$ distilled water for injection) compared with those not containing a preservative (such as $0.9 \%$ sodium chloride for injection and distilled water for injection). Therefore, in nebulization solutions not containing a preservative, particular attention to microbial contamination is necessary. In nebulization solutions

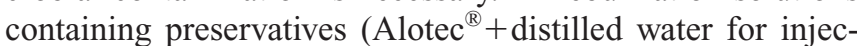
tion, Inolin ${ }^{\circledR}+$ distilled water for injection, Asupul ${ }^{\circledR}+$ distilled water for injection, Bisolvon ${ }^{\circledR}+$ distilled water for injection), though the preservatives contained in the products were originally diluted $1: 2-10$, the antibacterial activity of the preservatives can be expected. However, in 1:2-10 dilutions of some nebulization solutions containing preservatives $\left(\right.$ Meptin $^{\circledR}+$ distilled water for injection, Venetlin ${ }^{\circledR}+$ distilled water for injection), the antibacterial activity of the preservatives cannot be expected (Fig. 5). Therefore, there is a possibility that microbial contamination occurs even in nebulization solutions containing preservatives if they are diluted. In addition, the water activity of undiluted products or their $1: 2$ - 10 dilutions was $94.3-96.7$, being appropriate for microbial proliferation. The $\mathrm{pH}$ of undiluted products or their $1: 2-10$ dilutions was $2.8-4.7$, which is not optimal but allows for microbial proliferation. ${ }^{14,15)}$ Therefore, attention to microbial contamination is necessary, even for nebulization solutions containing preservatives when they are diluted. 
(1) Meptin ${ }^{\circledast}$ inhalation solution

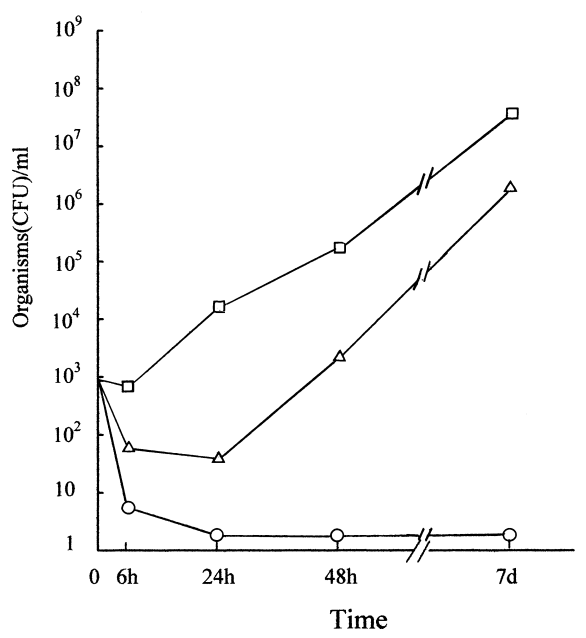

(3) Alotec $^{\circledR}$ inhalation solution

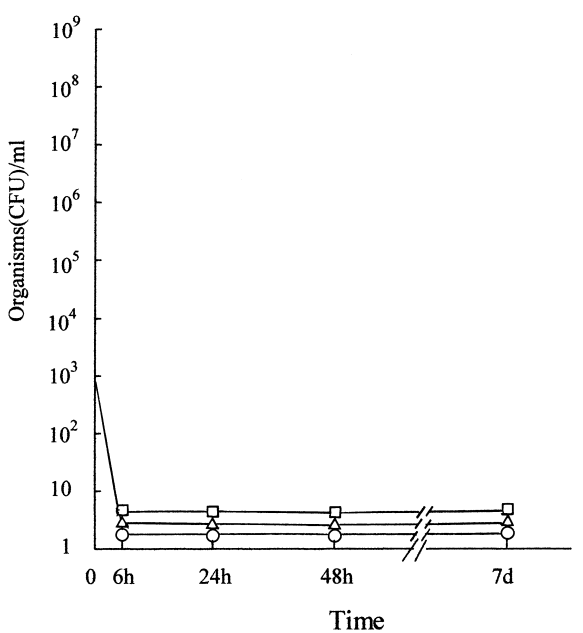

(5) Asupul $^{\circledR}$ inhalation solution

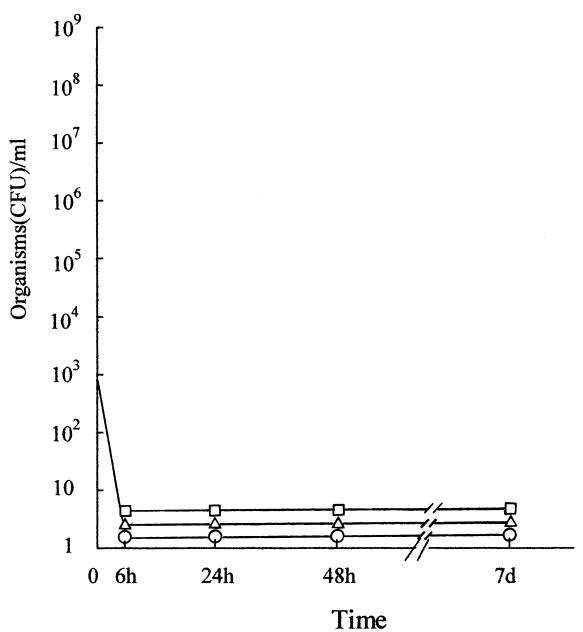

(2) Venetlin ${ }^{\circledR}$ inhalation solution

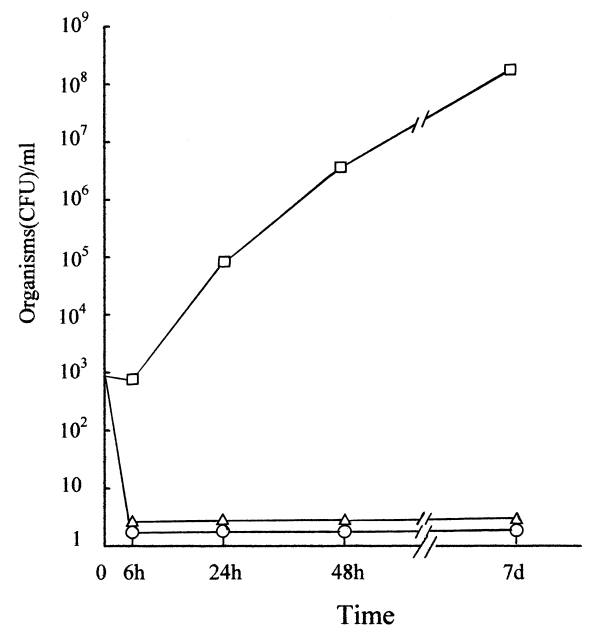

(4) Inolin ${ }^{\circledR}$ inhalation solution

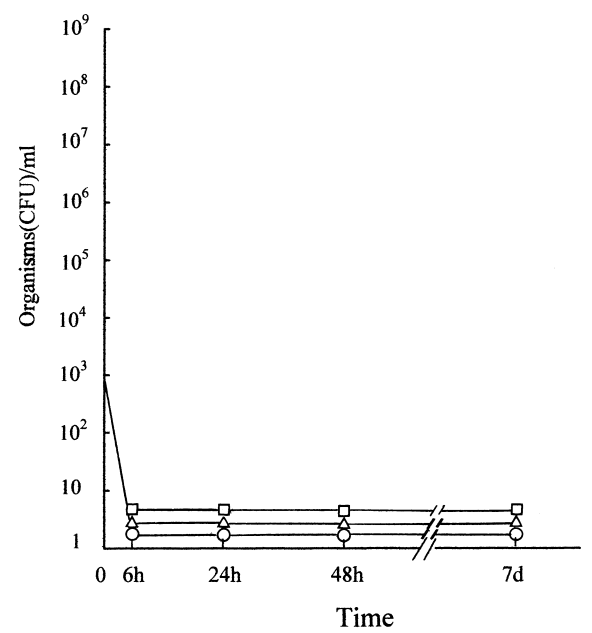

(6) Bisolvon ${ }^{\circledR}$ inhalation solution

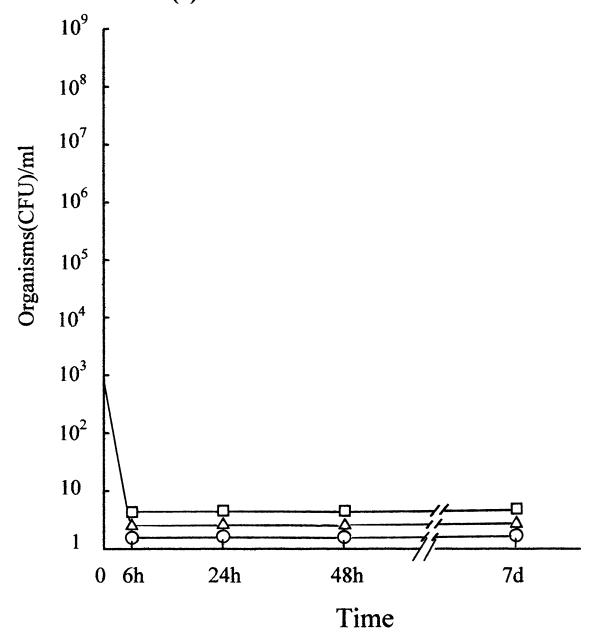

Fig. 5. Viability of Burkholderia cepacia at $30^{\circ} \mathrm{C}$ in Each Nebulization Solution Containing Preservative: Undiluted Solutions (O), Two-Fold Diluted Solutions $(\triangle)$, and Ten-Fold Diluted Solutions $(\square)$ 


\section{REFERENCES}

1) Reboli A. C., Koshinki R., Arias K., Marks-Austin K., Stieritz D., Stull T. L., Infect. Control Hosp. Epidemiol., 17, 741-743 (1996).

2) Hamill R. J., Hoston E. D., Georghiou P. R., Wright C. E., Koza M. A., Cadle R. M., Goepfert P. A., Lewis D. A., Zenon G. J., Clarridge J. E., Ann. Intern. Med., 122, 762-766 (1995).

3) Botoman M. J., Krieger R. A., J. Hosp. Infect., 10, 204-208 (1987).

4) Sanders C. V., Luby J. P., Johanson W. G., Barnett J. A., Sanford J. P., Ann. Infect. Med., 73, 15-21 (1970).

5) Pierce A. K., Sanford J. P., Thomas G. D., Leonard J. S., N. Engl. J. Med., 282, 528-530 (1970).

6) Mertz J. J., Scharer L., McClement J. H., Am. Rev. Respir. Dis., 95, $454-461(1997)$

7) Ringrose R. E., McKown B., Felton F. G., Barclay B. O., Muchmore H.
G., Rhoades E. R., Ann. Intern. Med., 69, 719-729 (1968).

8) Oie S., Kamiya A., Microbios, 82, 109-113 (1995).

9) Adachi T., Oie S., Kamiya A., Chemotherapy (Tokyo), 41, 195-199 (1993).

10) Witek T. J., York R., Noonan R., Topf B., Hebb H. W., Kowalczyk J. S., Dobuler K., Respir. Care, 28, 1306-1312 (1983).

11) Gelbart S. M., Reinhardt G. F., Greenlee H. B., J. Clin. Microbiol., 3, 62-66 (1976).

12) Rhoades E. R., Ringrose R., Mohr J. A., Brooks L., McKown B. A., Felton F., Arch. Intern. Med., 127, 228-232 (1971).

13) Miyano N., Oie S., Kamiya A., Biol. Pharm. Bull., 26, 671-674 (2003).

14) Entrekin D. N., J. Pharm. Sci., 50, 743-746 (1961).

15) Leistner L., Rodel W., "Inhibition and Inactivation of Vegetative Microbes," Academic Press, London, 1976, pp. 219-237. 